\title{
Somatotype of male and female judokas according to weight categories
}

\author{
Roberto Roklicer ${ }^{1}$, Dragan Atanasov ${ }^{2}$, Filip Sadri ${ }^{1}$, Dzenan Jahic ${ }^{3}$, Danilo Bojanic ${ }^{4}$, \\ Milovan Ljubojevic ${ }^{4}$, Tatjana Trivic ${ }^{1}$, Patrik Drid ${ }^{1,4}$ \\ ${ }^{1}$ Faculty of Sport and Physical Education, University of Novi Sad, Novi Sad, Serbia; ${ }^{2}$ Faculty of Sport, University Union \\ - Nikola Tesla, Belgrade, Serbia; ${ }^{3}$ Orthopaedics and Traumatology Clinic, Sarajevo University Clinical Center, Sarajevo, \\ Bosnia and Herzegovina; ${ }^{4}$ Faculty of Sport and Physical Education, University of Montenegro, Niksic, Montenegro
}

\section{Summary}

Study aim: The body structure can play a determining role in the achievement of top judo performance, and it seems to influence the type of techniques applied. The aim of this study is to determine the somatotypes in male and female national level judokas across weight categories in order to observe possible differences among athletes.

Material and methods: A total of 61 male judokas (23.2 \pm 2.7 years old) and 37 female judokas (22.3 \pm 3.3 years old) participated in this study. Anthropometric variables were used to calculate somatotypes. Somatotypes were determined according to the Heath-Carter method. Analysis of variance and Tukey's post hoc test were used to determine differences between weight categories and obtained effect sizes $\left(\eta^{2}\right)$ were presented as well.

Results: Somatotype differences among weight categories in male and female judokas were observed. Generally, all categories could be classified in three somatotypes in male and female athletes.

Conclusions: The lightest categories were recognized as mesomorphic ectomorphs in females with an exception in the $-48 \mathrm{~kg}$ category, and ectomorphic mesomorphs in male athletes. The middle ones had the endomorphic mesomorph somatotype and the heaviest athletes presented somewhat more extreme cases of endomorphic mesomorphs, both in male and female judokas. According to the results obtained, judokas have a specific body composition in different weight categories. Therefore, coaches could create a specific training programme for athletes who belong to different somatotypes.

\section{Keywords: Combat sports - Somatochart - Skinfolds - Body type}

\section{Introduction}

Judo is a high-intensity intermittent combat sport, in which many physical attributes are necessary to achieve optimal technical-tactical development and competitive success $[3,6,7,11,24]$. High level of muscle power is required for the fight's decisive moments, such as throwing and counterattack techniques, with the goal to score points (i.e., Wazari) or to finish the combat (i.e., Ippon) [18]. The body structure can play a determining role in the achievement of top judo performance $[1,4,14,16]$, and it seems to influence the type of techniques applied $[5,9,10]$. Body fat is generally low for these athletes, except for the heavyweight competitors [11, 22].

Since judo athletes are divided by age and weight categories, their body mass needs to be controlled continuously, in order to have an optimal performance. Judo athletes often have to maintain their body mass on a daily basis, particularly during the in-season period. The way of maintaining the bodyweight means using the rapid weight loss (RWL) methods for cutting weight when preparing for the competition, which may often have negative implications for athletes' health [7]. In combat sports, such as judo, weight management plays a very important role.

The body structure is related to attaining the elite level in judo and it may influence the type of techniques applied during a match $[9,12]$. The authors found key factors which determine champion levels, emphasising the importance of somatic build for specialisation in sport [2]. Certain research suggests that there are relationships between somatotype and the level of sports achievement in martial arts [8, $13,18,19]$. When comparing somatotypes, both in athletes and the general population, males tend to be more often the mesomorphic type compared to females, while females most often have the endomorphic type of body. The aim of 
this study is to determine the somatotypes of male and female judokas across weight categories in order to observe possible differences among athletes. From a practical point of view, it means the coaches could create a training programme for individual demands of judokas in accordance with their gender, weight category and body type.

\section{Materials and methods}

\section{Participants}

The sample consisted of 61 male judokas $(23.2 \pm 2.7$ years) and 37 female judokas ( $22.3 \pm 3.3$ years). Participants were divided into seven official weight categories (males: $-60 \mathrm{~kg},-66 \mathrm{~kg},-73 \mathrm{~kg},-81 \mathrm{~kg},-90 \mathrm{~kg},-100 \mathrm{~kg}$, $+100 \mathrm{~kg}$; females: $-48 \mathrm{~kg},-52 \mathrm{~kg},-57 \mathrm{~kg},-63 \mathrm{~kg},-70 \mathrm{~kg}$, $-78 \mathrm{~kg},+78 \mathrm{~kg}$ ). All athletes were competitors at the seniors' Serbian national championship (2018) and each of them had a master belt $\left(1^{\text {st }}-5^{\text {th }}\right.$ Dan $)$, which were the inclusion criteria for participating in the study. Informed written consent was obtained from each subject, and all procedures were performed in accordance with the Declaration of Helsinki. The study was approved by the local institutional review board (IRB).

\section{Testing procedure}

Anthropometric variables were collected following the protocol developed by the International Society for the Advancement of Kinanthropometry (ISAK). Anthropometric variables included body mass, height, 4 skinfolds (triceps, subscapular, supraspinale and medial calf), 2 girths (arm and medial calf) and 2 breadths (femoral and humeral epicondyles). Body height was measured to the nearest $0.5 \mathrm{~cm}$ using a Martin anthropometer (GPM, Switzerland). Weight was measured to the nearest $0.1 \mathrm{~kg}$ using a balance beam scale (Avery Ltd., St. Albans, UK). Skinfold thickness was obtained using a John Bull caliper (British Indicator Ltd., UK) accurate to $0.1 \mathrm{~mm}$. The girths were performed using a Gulick anthropometric tape (Creative Health Products, Plymouth, USA), while diameters were measured with small spreading calipers (Siber Hegner, Switzerland). Skinfolds were taken three times at each point in a rotation system and the mean of 3 measurements was used in the analysis. The same trained technician took all measurements. Somatotypes were determined according to the Heath-Carter method (1990) [2].

\section{Statistical analysis}

Results obtained are presented as mean values and standard deviation $( \pm)$. Analysis of variance and Tukey's post hoc test were used to determine differences between weight categories and obtained effect sizes $\left(\eta^{2}\right)$ were presented as well. The level of significance was set at $5 \%$. All analysis was conducted using IBM SPSS Statistics 20.

\section{Results}

According to the results obtained, male judokas differed in body height in relation to the weight category. As the weight throughout the categories increased, body height increased proportionally. In skinfolds, differences were found only between the skinfolds of the back, and groups differed from the heaviest weight category. Girths differed only between the first three light weight categories $(-60 \mathrm{~kg},-66 \mathrm{~kg},-73 \mathrm{~kg})$ compared to other heavier categories $(-81 \mathrm{~kg},-90 \mathrm{~kg},-100 \mathrm{~kg},+100 \mathrm{~kg})$. In elbow and knee diameters, we can see that all categories differed from each other, but only the value of knee diameter in the $-66 \mathrm{~kg}$ category was lower compared to other categories. According to weight category, athletes differed in their somatotype (mesomorph and ectomorph) (Table 1).

Regarding girls' results, it can be observed that girls from the lightest (weight) category were mostly also the shortest ones, in comparison to other weight categories. In the skinfolds, differences were observed between categories in the triceps and back, and only the back skinfold of the heaviest category $(+78 \mathrm{~kg})$ differed from other categories. In terms of girth and diameter, the highest values are mainly present in respondents of the two heaviest female categories $(-78 \mathrm{~kg},+78 \mathrm{~kg})$, and they mostly differed from the other lighter weight categories. Unlike males, females differed in all three somatotypes according to weight category (Table 2).

Based on the somatochart, we see that male categories are mostly endomorphic-mesomorphic type, only the heaviest category presents extremely different type when compared to others (Fig. 1). By analyzing female somatotypes, one can observe that the three middle categories belong to an endomorphic-mesomorphic type, while the two heaviest categories and the lightest category $(-48 \mathrm{~kg})$ belong to a somewhat more extreme endomorphic-mesomorphic type, and subjects in the $-52 \mathrm{~kg}$ category belong to a mild mesomorphic-ectomorphic type (Fig. 2).

When skinfold values are observed, linear growth is observed among male and female judokas, with an exception for the comparison between two successive male categories, $-100 \mathrm{~kg}$ and $+100 \mathrm{~kg}$, where the lighter of the two has a higher value of the triceps as well as the supraspinale skinfold, $7.90 \pm 2.81 \mathrm{~mm}$ vs $7.85 \pm 0.78 \mathrm{~mm}$ and $9.80 \pm 6.24 \mathrm{~mm}$ vs $8.70 \pm 0.42 \mathrm{~mm}$, respectively. There is a similar observation for the comparison between $-73 \mathrm{~kg}$ and $-81 \mathrm{~kg}$ categories, when calf skinfolds are compared, where the lighter of these two categories had higher skinfold thickness $(7.77 \pm 2.02 \mathrm{~mm}$ vs $6.75 \pm 2.44 \mathrm{~mm})$. In female skinfold comparison between the weight categories, there is also linear growth, except for the two successive categories $-70 \mathrm{~kg}$ and $-78 \mathrm{~kg}$, where the lighter category has higher values in every measured skinfold. Once again, 


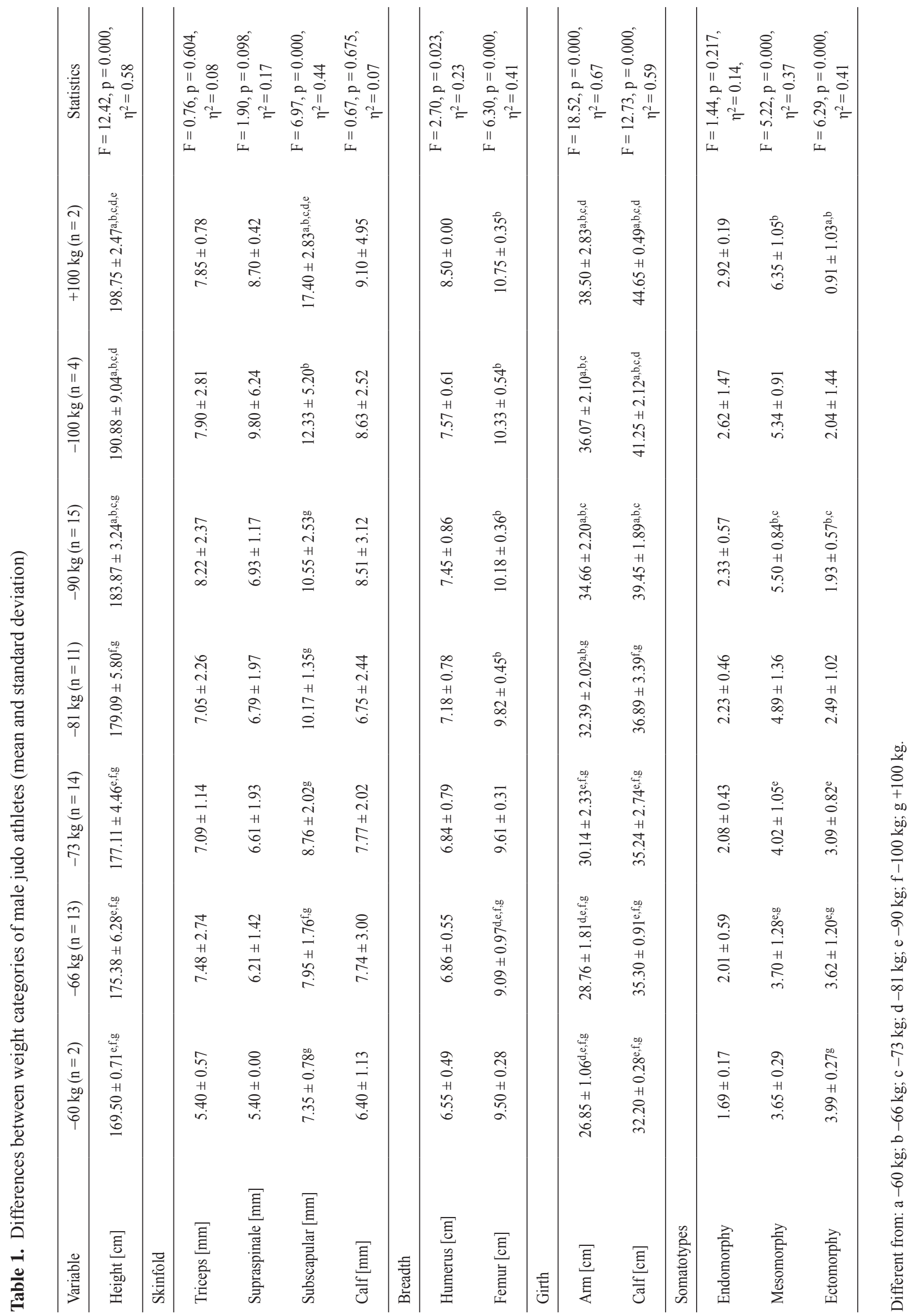




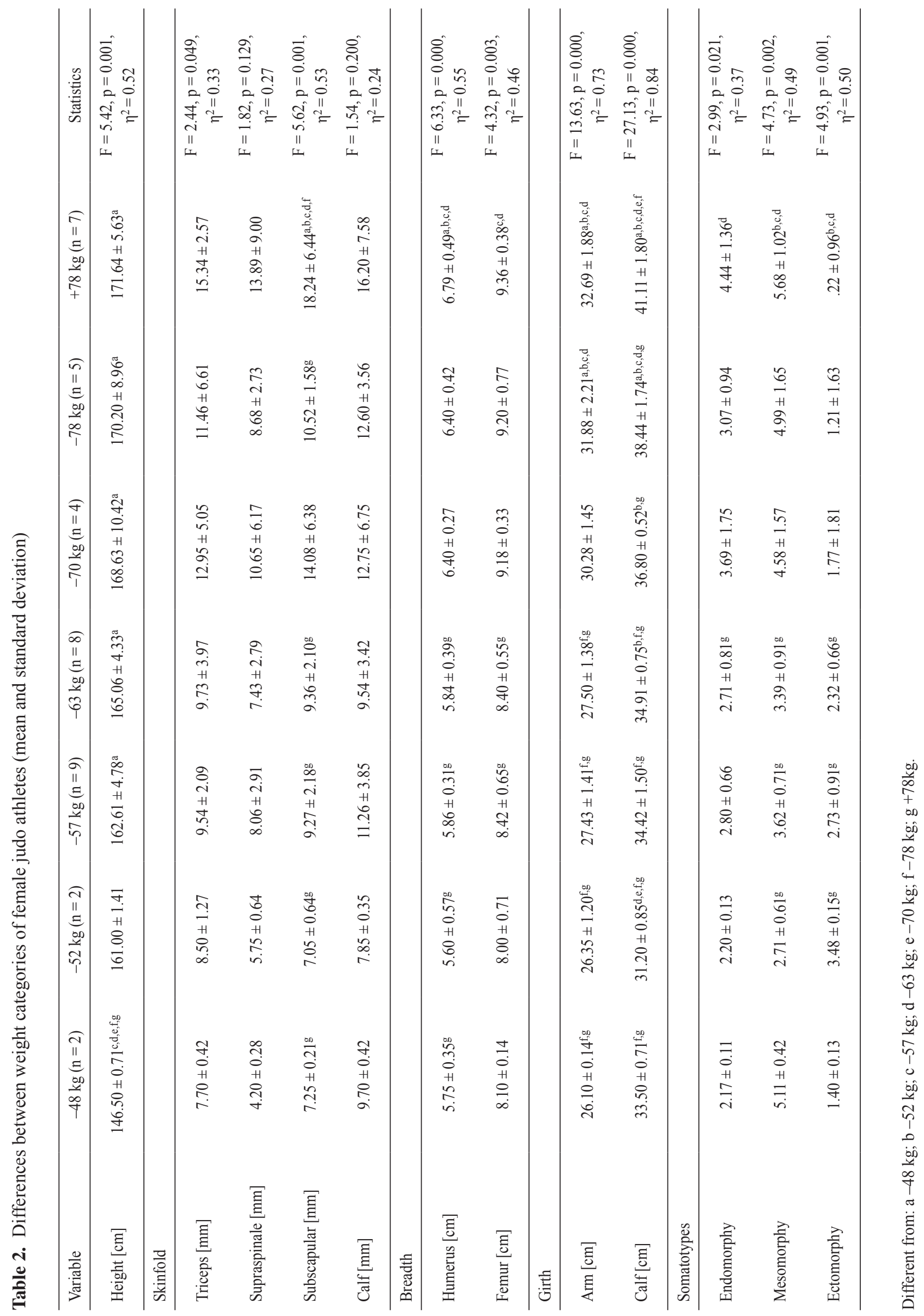




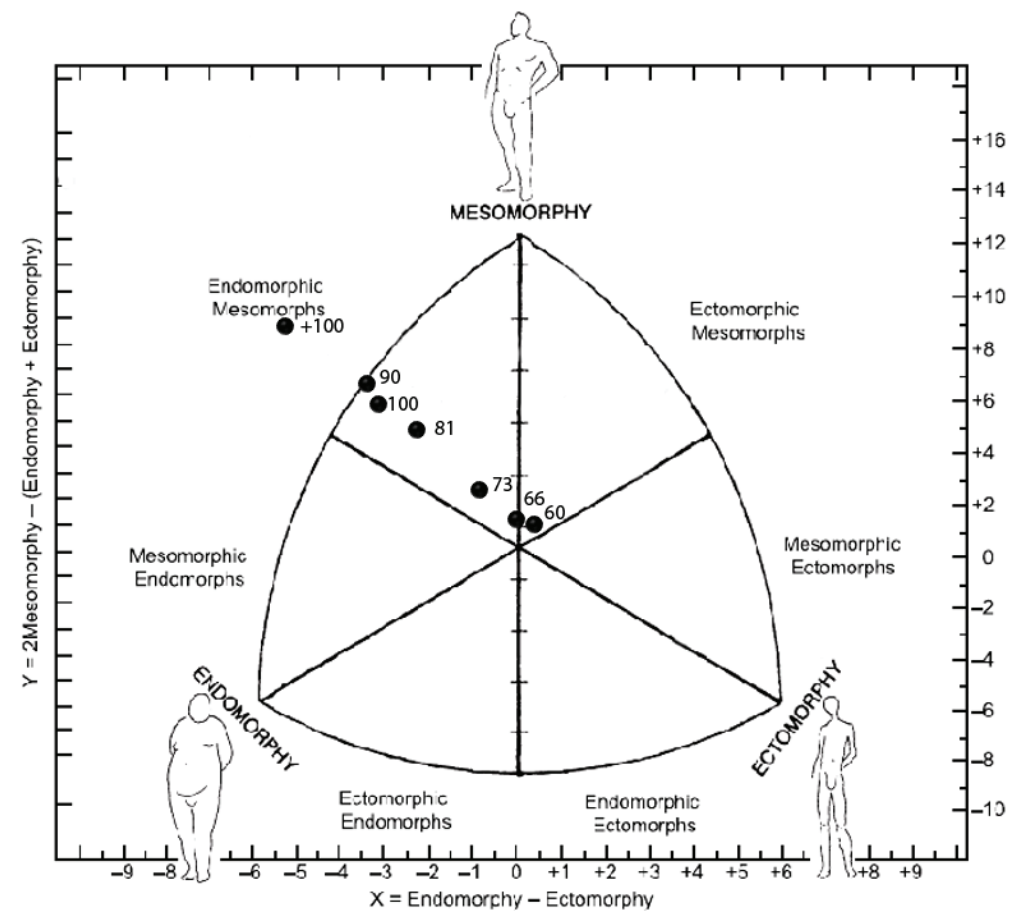

Fig. 1. Somatochart of male judo athletes by weight category

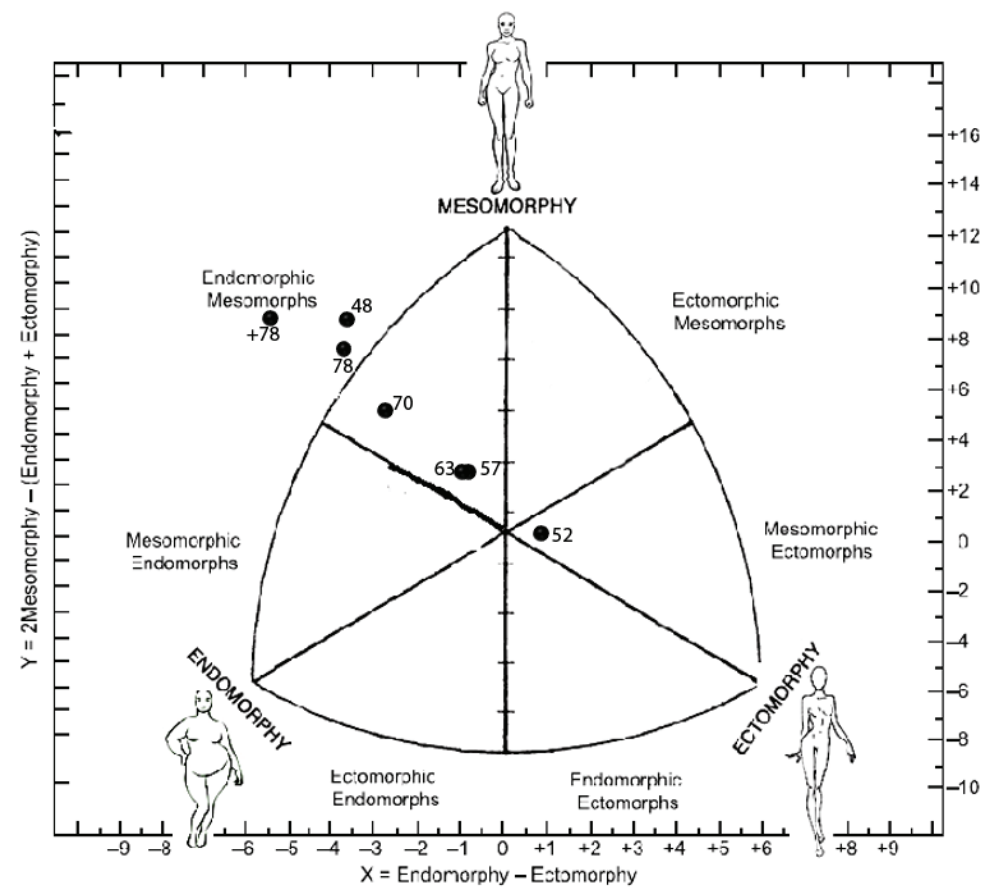

Fig. 2. Somatochart of female judo athletes by weight category

when comparing between two consecutive categories $-57 \mathrm{~kg}$ and $-63 \mathrm{~kg}$, higher values of calf skinfold were observed in the lighter weight category $(11.26 \pm 3.85 \mathrm{~mm}$ vs $9.54 \pm 3.42 \mathrm{~mm}$ ).

Humerus diameters in male judokas grew linearly through categories, while there was an exception in femur breadth between the $-60 \mathrm{~kg}$ and $-66 \mathrm{~kg}$ categories, with a higher value in the lighter category $(9.50 \pm 0.28 \mathrm{~cm}$ vs $9.09 \pm 0.97 \mathrm{~cm}$ ). Bone diameters in female judokas varied among weight categories in nonlinear fashion, but with values close to each other among consecutive categories.

Arm girth measurement results in male judokas differed in the two lightest categories compared to other five heavier ones. Calf girth values in the first three categories 
were different compared to the three heaviest categories, while the middle category $(-81 \mathrm{~kg})$ significantly differed from the heaviest two. When female girth measurement values are observed, the difference can be noted between the four lightest categories and the two heaviest in terms of arm girth. Calf girth values in the heaviest two categories were significantly higher when compared to all other lighter ones.

According to the results, the lightest male weight category $(-60 \mathrm{~kg})$ turns out to be the ectomorphic mesomorph body type. Presence of an ectomorphic component might be the result of a low body fat percentage among the lightest categories in combat sports. From the $-66 \mathrm{~kg}$ category to the $-100 \mathrm{~kg}$ category, according to their body types, athletes belong to endomorphic mesomorphs, which can be observed from Fig. 1. This body type is most likely the result of the high muscular component among male judokas. Only the heaviest male category had an extremely different somatotype compared to others. Athletes heavier than $100 \mathrm{~kg}$ had a more prominent endomorphic mesomorph somatotype. On the other hand, the mesomorphic ectomorph somatotype was present in the $-52 \mathrm{~kg}$ female category, as can be noted from Fig. 2. Three middle categories were endomorphic mesomorph, while the lightest and the heaviest two $(-48 \mathrm{~kg},-78 \mathrm{~kg}$ and $+78 \mathrm{~kg})$ categories were somewhat more extreme endomorphic mesomorphs than the others. Regardless of the various diameter, skinfold and girth measurement results, different body composition and somatotypes are observed across weight categories in males and females.

\section{Discussion}

There are several publications regarding the somatotype of judo athletes in the available literature. There is a study that suggests presence of higher muscle mass and lower fat percentage, lower endomorphic and higher mesomorphic components in male than in female judokas $[10,20]$. On the other hand, the lightest female competitor from our study $(-48 \mathrm{~kg})$ showed an extremely high endomorphic-mesomorph component. This occurred because of several reasons. First, she is an extremely short athlete, which is unusual even for that weight category. Since her body type turns out to be highly muscular, it should not be unusual for her to belong to this somatotype group. Additionally, compared to her body height, her body mass only adds up the endomorphic-component, which is why it makes her body type so specific. Except for this athlete, other somatotype differences appeared pretty much as expected. As in the study of Jagiello (2013) [15], body weight and height in male judokas increased linearly in our study as well. When observing the mean values of each (endomorphic, mesomorphic and ectomorphic) component of judokas, there are similarities with the results obtained in other research [17,21].

The Heath-Carter somatotyping revealed that heavyweight judokas had the highest level of endomorphy and mesomorphy. Similar results were reported in a study conducted by Stachon et al. [22]. A study by SterkowiczPrzybycien et al. [23] showed that all the athletes mainly had endomorphic mesomorph somatotype with balanced mesomorph appearance in some cases. In this research the authors also reported the endomorphic mesomorph as a typical somatotype in females. In a study done on Spanish senior judokas, both male and female athletes presented endomorphic mesomorph somatotype [3], which is also in line with results from our study. Knowing the fact that judokas change their body weight several times during the season, it could go along with somatotype alterations. During the weight cutting period coaches should consider making a diet plan for individual athlete in collaboration with a nutritionist. Doing so, elite judokas could use gradual weight loss methods instead of aggressive ones.

\section{Conclusions}

Since judo is a weight-classified sport, our study explored all 7 categories, both male and female. Subdividing the judo athletes' somatotypes resulted in roughly three groups of different body types overall. The results from our study show similarity with results from other earlier studies that investigated the somatotype of judokas. As the current study showed somatotype differences among weight categories, coaches need to apply their knowledge and skills so as to prepare judokas according to the specific body type in order to enhance their performance.

\section{Conflict of interest: Authors state no conflict of interest.}

\section{References}

1. Buśko K., Pastuszak A., Kalka E. (2017) Body composition and somatotype of judo athletes and untrained male students as a reference group for comparison in sport. Biomed. Hum. Kinet., 9: 7-13.

2. Carter J.R.L., Heath B.H. (1990) Somatotyping: Development and Applications. Cambridge: Cambridge Universtity Press.

3. Casals C., Huertas J.R., Franchini E., SterkowiczPrzybycień K., Sterkowicz S., Gutiérrez-García C., Escobar-Molina R. (2017) Special judo fitness test level and anthropometric profile of elite Spanish judo athletes. J. Strength. Cond. Res., 31: 1229-1235. 
4. Claessens A., Beunen G., Wellens R., Geldof G. (1987) Somatotype and body structure of world top judoists. J. Sports. Med. Phys. Fitness, 27: 105-113.

5. Dimitrova N. (2009) Biodynamic analysis of the Uki Goshi technique in judo. EQOL, 1: 38-41.

6. Dimitrova N. (2017) Biomechanical assessment of the physical activities of the technique Uchi-mata in judo sport. Act. Phys. Edu. Sport, 7: 180-181.

7. Drid P., Casals C., Mekic A., Radjo I., Stojanovic M., Ostojic S.M. (2015) Fitness and anthropometric profiles of international vs. national judo medalists in half-heavyweight category. J. Strength. Cond. Res., 29: 2115-2121.

8. Drid P., Krstulovic S., Erceg M., Trivic T., Maksimovic N., Stojanovic D.M., Ostojic S.M. (2019) The effects of rapid weight loss on body weight, total body water and circulating markers of creatine metabolism in judokas. Kinesiology, 51(2): 158-160.

9. Drid P., Tabakov S., Eliseev S., Selimovic N., Jaksic D., Trivic T., Ostojic S. (2018) Somatotypes of elite male and female junior sambo athletes. Arch. Budo., 14: 189-195.

10. Franchini E., Takito M.Y., Bertuzzi R.C.M. (2005) Morphological, physiological and technical variables in highlevel college judoists. Arch. Budo., 1: 1-7.

11. Franchini E., Del Vecchio F.B., Matsushigue K.A., Artioli G.G. (2011) Physiological profiles of elite judo athletes. Sports. Med., 41: 147-166.

12. Franchini E., Huertas J.R., Sterkowicz S., Carratala V., Gutierrez-Garcia C., Escobar-Molina R. (2011) Anthropometrical profile of elite Spanish Judoka: Comparative analisys among ages. Arch. Budo., 7: 239-245.

13. Franchini E., Sterkowicz-Przybycień K., Takito M.Y. (2014) Anthropometrical Profile of Judo Athletes: Comparative Analysis Between Weight Categories. Int. J. Morphol., 32: 36-42.

14. Gualdi-Russo E., Graziani I. (1993) Anthropometric Somatotype of Italian Sport Participants. J. Sport. Med. Phys. Fitness, 3: 282-291.

15. Jagiełło W. (2013) Differentiation of the body build in judo competitors of the men's Polish national team, Arch. Budo., 9: 117-123.

16. Krstulovic S., Zuvela F., Katic R. (2006) Biomotor systems in elite junior judoists. Coll. Antropol., 30: 845-851.

17. Lewandowska J., Buśko K., Pastuszak A., Boguszewska K. (2011) Somatotype variables related to muscle torque and power in judoists. J. Hum. Kinet., 30: 21-28.
18. Miarka B., Panissa V.L.G., Julio U.F., Del Vecchio F.B., Calmet M., Franchini E. (2012) A comparison of timemotion performance between age groups in judo matches. J. Sports. Sci., 30: 899-905.

19. Monterrosa Quintero A., da Rosa Orssatto L.B., Pulgarín R.D., Follmer B. (2019) Physical Performance, Body Composition and Somatotype in Colombian Judo Athletes. Ido. Mov. Culture. J. Martial. Arts. Anthrop., 19: 56-63.

20. Noh J.W., Yang S.M., Kim J.H., Lee J.U., Kim M.Y., Lee L.K., Park B.S., Lee W.D., Shin Y.S., Kim D.H., Kim S.J., Kim. I.H., Kwak T.Y., Lee T.H., Kim J.Y., Kim J. (2018) Somatotype analysis of Korean combat sport athletes based on weight divisions. Arch. Budo., 14: 169-178.

21. Quintero A.M., da Rosa Orsatto L.B., Pulgarin B.D., Follmer B. (2019) Physical performance, body composition and somatotype in Colombian judo athletes, Ido. Mov. Culture. J. Martial Arts Anthrop., 19: 56-63.

22. Stachoń A., Pietraszewska J., Burdukiewicz A., Andrzejewska J. (2014) The diversity of body composition, body proportions and strength abilities of female judokas in different weight categories. Arch. Budo., 10: 37-46.

23. Sterkowicz-Przybycień K., Błach W., Żarów R. (2012) Somatotype components in judoists. Journal of Combat Sports and Martial Arts, 2: 73-78.

24. Trivic T., Casals C., Drid P. (2016) Physiological responses during arm and leg aerobic power tests in elite female judokas. EQOL, 8: 21-24.

\section{Received 08.08.2019 \\ Accepted 15.01.2020}

(C) University of Physical Education, Warsaw, Poland

\section{Acknowledgments}

Supported by the Serbian Ministry of Education, Science and Technological Development (179011), Provincial Secretariat for Higher Education and Scientific Research (142-451-2094/2019-02) and Faculty of Sport and Physical Education. 